\title{
1. Introduction and general overview of economic happiness
}

Through ancient, medieval, and modern times, people have wrestled with the pursuit of happiness. Humans have tried to locate happiness from the points of view of the divine, of man on earth, and some combination referred to as a God-man or superman. The earth was created with resources that can make a person happy by some effort, action, or choice guided by reason. Some psychologists think that to look for happiness through intuition, chance, or grace is a primitive concept. Some philosophers think that there is no path or method to happiness. A set of people think that one can obtain happiness through grace or a gift of God, the Creator, or a supernatural being. Another set of people think that happiness comes as a side-thing from living a virtuous life, and many people think that it correlates with gaining wealth and income.

The very definition of being human spans those views. In the twentieth century, the word 'humanism' was purged of transcendental religious belief, and specialized to human welfare in earthly life. In Greek times, the focus was on human affairs, but by the time of the Renaissance, this was coupled with the belief in God (Inwood, 1999, 99. 100-101). For instance, the Dutch philosopher Erasmus of Rotterdam (1466-1536) was a Christian and a humanist, but the German monk Martin Luther (1483-1546) backed away from humanism and moved more towards the soul. Now, humanism is focused on the welfare of the people and not on transcendent religion.

From the individual point of view, Ludwig von Mises, a founder of the libertarian school of economics, 'defines human action as the striving for happiness' (Mises, 1996 [1949], p. 14). This view holds that we are personally responsible for our own happiness. Humans use their will and understanding to make choices in life, and must live with the consequences, good or bad. The scope of this view is rather wide, including improvement of one's ego, satisfaction of one's appetite, people seeking higher or ideal satisfactions, people who seek bliss, and so on (pp. 14-15).

From the social point of view, Kenneth Galbraith, a prominent institutionalist, viewed happiness as 'The Good Society'. According to Galbraith, 'In the good society, all its citizens must have personal liberty, basic 
well-being, racial and ethnic equality, and opportunity for a rewarding life' (Galbraith, 1996, p.4). This means that the economics of the good society must work for everyone. It must have strong growth and associated employment and income (p. 24). The bottom line is that the good society is a rule-driven rather than a market-driven path to success.

Another welfare approach to happiness started with the Bergson welfare function (Bergson, 1982). This function uses an index of utilities, $U_{i}, i=1 \ldots, N$, for each of $N$ people in society. In such a model, one can set up multiple measures of social happiness depending on the social equity one is after. Many analyses are satisfied with just the concept of social efficiency, which is associated with the concept of Pareto efficiency. Pareto's concept is a relation that states that the utilities each individual gets, $U_{i}$, are not dominated by any other utilities, $\bar{U}_{i}$. So it is not the case that, $\bar{U}_{i}>U_{i}$ for all $i=1, \ldots \ldots, N$. It is well known that Nicholas Kaldor, Sir John Hicks, and Paul Samuelson extended this criteria to equity issues such as consumer surplus, and that Sen's paradox found it in conflict with individual rights (Gravel, 2001, p. 164).

\section{SOME GENERAL MEASURES OF HAPPINESS}

The correlation between happiness, money, wealth, utility, and income has been made throughout history. For The Good Society:

There is, first, the absolute, inescapable requirement that everyone in good, even decent, societies have a basic source of income. And if this is not available from the market system, as it is now called, it must come from the state. Nothing, let us not forget, sets a stronger limit on the liberty of the citizen than a total absence of money. (Galbraith, 1994, p. 167)

One measure of the welfare of a nation is the gross domestic product (GDP). Adam Smith, the father of classical economics, wanted to grow the wealth of a nation most rapidly. He chose a self-interest system partly because people who follow their self-interest unintendedly benefit others. Ever since, economists have been concerned with where the system underperforms. For David Ricardo, it was pushing against diminishing returns from nature; for Thomas Malthus, it was rapid population growth; and for Karl Marx, it was class conflict. The major problem with Smith's system is not that wealth is not produced rapidly, but that it becomes unequally distributed. The Good Society wanted everyone to gain fairly.

In neoclassical economics, labor is free to search for its greatest reward, which under the neoclassical system is attained where the marginal product of labor matches its real wage rate. This is easily translated into value of 
marginal product by multiplying the marginal product by prices, implying the use of money. While that procedure works well for labor, it is met with resistance with regard to the marginal product of capital, for the simple reason that capital cannot be easily defined. The state of this discussion is still unsettled, taking the form of debates between the Cambridge Schools at MIT in the USA and the University of Cambridge in the United Kingdom.

Many questions surround the use of GDP as a measure of the quality of life. According to Arthur Cecil Pigou, two propositions are discernable: namely, that 'the elements of welfare are states of consciousness', and that 'welfare can be brought under the category of greater and less', for which money is a practical measure (Pigou, 1920, pp.10-11). While GDP is only a part of total economic welfare, the part does affect the whole. This can lead to changes in the non-economic part of total welfare to negate the economic effects (p.12). Today, a major concern is that the cost of economic growth is destroying the quality of life (Beckerman, 1974, p. 2).

Economists consider a plurality of concepts when examining income in correlation with happiness. The popular models are absolute income, relative income, and permanent income. John Maynard Keynes related aggregate consumption, $C$, mainly to aggregate disposable income, $Y$, defined as income less taxes and transfer payments. This is a psychological law stating that consumption increases with income but not by the same proportion. The slope of $Y$ is called the marginal propensity to consume, which Keynes estimated to be between 60 to 70 percent in the short run (Keynes, 1972-89, Vol. VII, p. 128). The Keynesian consumption function sparked a new research programme. Milton Friedman's work on the permanent income hypothesis (PIH), and Franco Modigliani's work on the lifecycle hypothesis (LCH) (Modigliani, 1980 [1949]) were in large part the catalysts for their Nobel Prizes in 1976 and 1985, respectively. The PIH-LCH models reconciled anomalies in the prediction of Keynes's short-run model. A major anomaly was that the average propensity to consume was over 90 percent, whereas short-run MPC was between 60 and 70 percent. Franco Modigliani (1980 [1949]) and James Duesenberry (1949) reconciled the differences by postulating a previous peak income in the consumption function. Whereas Modigliani's work evolved into his LCH hypothesis, James Duesenberry's work evolved into his relative income hypothesis (RIH).

In more modern research, Robert Frank has expanded and articulated the RIH paradigm in relation to the question of how current relative consumption will dominate future relative consumption (Frank, 2009, pp. 70-73, 193-195). Parents who prefer to buy a house in a good school district now may be negatively affecting their future consumption after 
retirement. Conversely, spending now on a suit for a job interview may have a positive impact on future income. The experience of low relative consumption now may also set expectations for low relative consumption in the future. Juliet Schor's 'new consumerism' is also based on RIH, positing that consumers elevate their consumption to unsustainable levels that lead to mounting debts and bankruptcies, as well as longer working hours (Schor, 1998). John Muth introduced rational expectation into permanent income by an exponentially moving average equal to the conditional expected value under rational expectations (Muth, 1960). Robert Lucas expanded the rational expectation concept by shifting the meaning of the consumption function from relating consumption and income, to relating permanent income and observed income (Lucas, 1976). Robert Hall rescued the consumption function from that line of attack by postulating that only surprising events could be responsible for unexpected results. Hall tested his consumption function in the form $C_{t+1}=\lambda C_{t}+$ error ${ }_{t}$, a random walk model, which is easy to measure (Granger, 1999, pp.42-43).

\section{UTILITY AS A METHOD}

The early approach of Jeremy Bentham suggested a cardinal measurement of utility. As Stigler puts it, 'Bentham has indeed planted the tree of utility. No reader could overlook the concept of utility as a numerical magnitude, and the implications for economic analysis were not obscure. But they were overlooked' (Stigler, 1965, pp. 74-75). Some salient facts about Bentham's view of utility include the following:

1. It is of the form of a motto: Actions are good that promote the 'greatest happiness of the greatest number' (Bentham, 1843, p. 5). Bentham intended this saying as an axiom in the sense of Euclid's axiom in geometry, but surmised that it has practical and empirical justifications.

2. Ethical values such as right and wrong are settled by the motto. If private property, for instance, makes the generality of people happy, then it is good; and if it makes then unhappy, then it is bad (Hobhouse, 1965 [1922], p. 15).

3. It is altruistic in the sense that it gives precision to the command: 'Love thy neighbor as thyself' (Hobhouse, 1965 [1922], p. 18).

4. Utility is additive. Total $(u)=u(x)+u(y)$, where $x$ and $y$ are commodities, and $u$ is utility. In the case of total social utility, Samuelson emphasized that it does not matter if a redistribution 'will hurt some and help others provided that those who are helped add more to the total utility than those who are hurt' (Samuelson, 1966a, p. 241). 
5. Later works on utility developed the ordinal utility concept, where $u(x, y)$. According to John Hicks, Vilfredo Pareto's work on the scale of preference was the start of ordinal utility. If 'we know, for the individual in question, how much utility he would derive from any given set of quantities of the goods on the market. Then we can deduce from this function (assuming always that he will prefer a higher to a lower utility) a scale of preferences; we can say of any two sets, whether he will prefer one to the other, or whether they will be indifferent to him' (Hicks, 1981, p. 6). This approach paved the way for the logic of choice method to utility analysis.

6. The difference between cardinal and ordinal utility is that the first will add up utilities of separate commodities $x$ and $y$ to get total utility, $u$, while the latter will consider joint consumption of $x$ and $y$, such as putting butter on your bread before eating it. Is cardinal superior to ordinal? Ordinal makes more common sense, but cardinal is the preferred tool for modern general equilibrium analyses.

\section{JOHN VON NEUMANN'S AND OSKAR MORGENSTERN'S UTILITY FUNCTION}

In their famous game theory book, these authors presented their expected utility theorem. With a set of axioms, they prove that a utility function exists that implies that decision-makers behave in a way to maximize their expected utility. To be more precise, they 'prove that those axioms imply the existence of at least one mapping (actually, of course, of infinitely many) of the utilities on numbers' (von Neumann and Morgenstern, 1953 [1944], p.617). In order to grasp the essence of this theorem, we look at Figure 1.1. The figure shows, how two outcomes become utility functions, and how a third outcome can be integrated into the framework by considering the attitude of the agent. This involves the use of axioms, such as the complete and continuous ones used in the figure.

Such results in Figure 1.1 can be the outcome of games whose end result on a spanning tree can be in the form of money. The money value will in turn map to utilities for a person. Ranking the utilities helps us to select the worst case and set its utility to zero, and to select the best case and set its utility to unity.

One can locate different amounts of money, say $x$ and $y$, on a horizontal line, and measure their utility on a vertical line in the Cartesian plane. Between $x$ and $y$ so configured, one can place another dollar amount, $z$, between them and consider varying probability weight, $\propto$, to make $x$ and $y$ indifferent to $z$, written $\propto x+(1-\propto) y \sim z$. We can then proceed with 


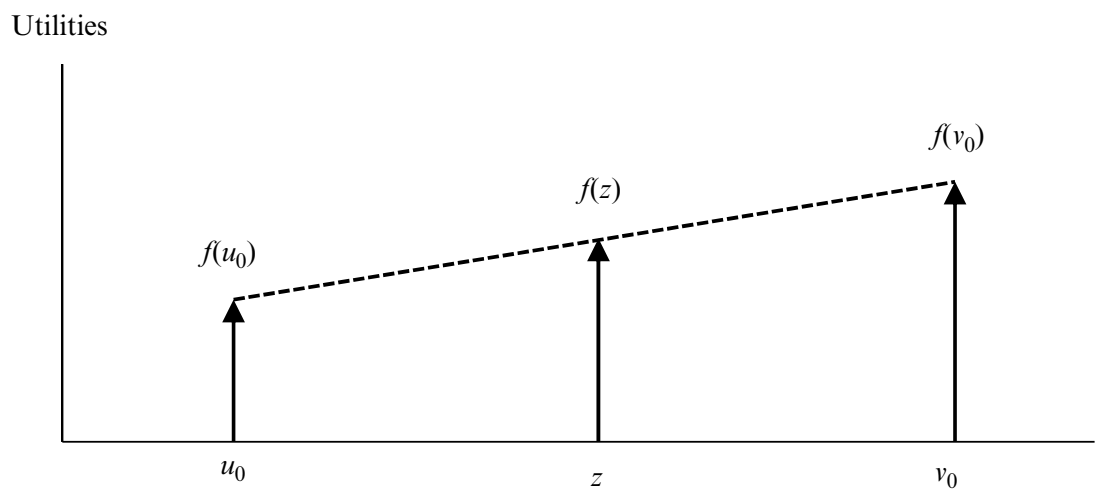

1. Given $u_{0}, v_{0}$. By the completeness axiom, rank them as $u_{0}<v_{0}$.

2. Set the utility function for $u_{0}, v_{0}: f\left(u_{0}\right)=0 ; f\left(v_{0}\right)=1$.

3. From a lottery (a probability distribution) with the utility function yielding $\propto f\left(u_{0}\right)+(1-\propto) f\left(v_{0}\right)$, where $0<\propto<1$.

4. One can now use the continuity axiom to change the value of $\propto$ in order to get the following indifferent relationship.

$$
\propto f\left(u_{0}\right)+(1-\propto) f\left(v_{0}\right) \sim Z
$$

This will make $f(z)$ fall on a line connecting $f\left(u_{0}\right)$ and $f\left(v_{0}\right)$. All such $f(z)$ points will stand for risk-neutral situations.

\section{Figure 1.1 Von Neumann-Morgenstern utility concept}

John von Neumann and Oskar Morgenstern's utility function that joins $x$ and $y$ with a line going through $z$, which yields a risk-neutral situation with linear utility functions.

Other measures of risks include a risk-averse concave utility function from joining $x$ and $y$ with an arc over $z$, and a risk-loving convex utility function joining $x$ and $y$ with an arc under $z$. These functions allow us to have an index to measure risk. One such measure is the Arrow-Pratt measure of risk-aversion by dividing the second derivative of the utility function by its first derivative to get $-\left(u^{\prime \prime} / u^{\prime}\right)$. This formula can measure risk due to income, wealth, or a combination of them using wealth as a constant.

Utility theory has been used by Daniel Bernoulli (1954 [1738], pp.29-20) to explain a paradox in expected money value (EMV) calculation in the famous St Petersburg paradox. The situation arises because most people will choose a $\$ 20$ certainty equivalent over a lottery that pays $\$ 1$ for a streak toss of heads in a coin-toss whose EMV = \$infinite (Bernoulli, 1954 [1738]). Bernoulli proposed the maximization of expected utility rather than EMV. John von Neumann and Oskar Morgenstern have given 
expected utility theory an axiomatic base (von Neumann and Morgenstern, 1953 [1944]). They were able to derive a utility function $U: X \rightarrow R$, that is, $U$ takes $X$ to a real number. So, one can use utility and not indifference curves for choice analysis. The axioms they use are:

Completeness. It means given two elements of utility, $u, v$, then either $u>v, v>u$, or $u=v($ p. 26).

Transitivity. It means 'whenever $x$ dominates $y$ and $y$ dominates $z$, then also $x$ dominates $z$ ' (p. 38).

Continuity. If $v$ is preferable to $u$, then even a chance $1-\propto$ of $v$, alternatively to $u$ is preferable (p.27). This can be restated as points in the neighbourhood of $v$ are preferred to $u$.

Independence. For every $P, Q, R \in L$, and if $P$ is preferred to $Q$, then a linear combination of $P$ with $R$ will be preferred to the same linear combination of $Q$ with $R$, that is, $\propto P+(1-\propto) R>\propto Q+(1-\propto) R$.

Utility theory figures in the second welfare theorem in economics. If some people are not in their equilibrium position, then it is better to put money in their hands and let them choose the commodities associated with utilities to bring them back to equilibrium. To emphasize, the money method is better than giving people food stamps or other in-kind payments, because money will enable their choice of commodities, so that their demand will be incorporated into the market system to make a more efficient and optimal equilibrium system.

In general equilibrium welfare economics, indifference curves are extracted from utility curves. Two traders' curves can be put into a back-to-back relationship in an Edgeworth box, and Pareto's optimal outcome is sought (Dobb, 1969, p.14). More modern applications use a net trade diagram (Ellickson, 1997, p. 19). Through computational general equilibrium analysis, welfare benefits under free trade can be computed for various aggregation of countries or regions of the world. One of our studies calculate the benefits of United States and the Economic and Monetary Union (EMU) of the European Union using that method, when the EMU had just formed. It shows that 'welfare benefit to the EMU as a group ... exceeded the total benefits of individual countries if they were non-members' (Ramrattan et al., 2001, p. 263). In another of our studies we estimated the welfare benefit of Latin America versus the rest of the world. The results indicated through various scenarios that Latin America stands to gain welfare benefits via trade liberalization (Ramrattan et al., 2004, pp. 27-29). 


\section{A METRICAL MEASURE OF HAPPINESS}

In developing utility theory, Jeremy Bentham made the proposition of the greatest happiness for the most people. He suggested that pleasure should be measured by such variables as intensity, duration, certainty, propinquity, fecundity, purity, and extent. One can follow Robert McNaughton in translating this concept to a metrical measure of preferences (McNaughton, 1953). He specified an interval short enough for the experience of happiness to be the same in the moment. We can then compare those moments in experiences with another moment. Given two such moments in experiences, $x$ and $y$, we can have preference, $P$, and equivalent, $E$, relationships between them. Then, we can create axioms for metrical measurement as follows.

One assumption is that 'An individual's experience can be divided into intervals such that his happiness may vary from one interval to the next, but not within an interval. These intervals will be referred to as moments of experience' (p. 173). Another assumption is to apply the preference and equivalent operators on $x$ and $y$ to get either $P(x, y), P(y, x)$, or $E(x, y)$. A third assumption is that ordering moments of experiences is irrelevant in measuring happiness. So, given a pleasant and an unpleasant task, one should think that doing the unpleasant first and anticipating the pleasant is a better way to proceed. A fourth assumption holds that "when equals are added to equals the results are equal; and when equals are added to unequals the results are unequal in the same order' (p. 176). For instance, when we have $E(x, y)$, then for all $z$ and $w$, if $P(z, w)$ then $P(x \& z, y \& w)$, if $P(w, z)$ then $P(y \& w, x \& z)$, and if $E(z, w)$ then $E(x \& z, y \& w)$.

McNaughton's fifth assumption skirts the hazy areas of consciousness, unconsciousness, and death. A set of unconscious moments, $z$, does not count. So, given an experience, $x$, we can write $E(x \& z, x)$, which indicates that $z=0$. Death is such a moment in which happiness and unhappiness do not count. This might be a surprising conclusion for those who think that death is a release from an unhappy situation or a release from the body as a prison, as Socrates likened.

A sixth assumption states that 'if $x$ is happy then no matter how happy $y$ is it can be surpassed by enough experiences like $x$. If $x$ is unhappy then no matter how happy $y$ is it can be offset by enough experiences like $x$ ' (p.177). This can be related to the motto that a rolling stone gathers no moss. On the one hand, if one perseveres in one's task, one will reach the desired goal and be happy. Or if one perseveres and fails, then one can offset a happy state.

One is then interested in how comparisons can be measured in such a calculus. A seventh assumption states that, 'For every two individuals, 
there is a pair of moments, one from each individual, either both happy or both unhappy, which are empirically equivalent ... An interpersonal calculus will involve sets of moments not all of which are of the same individual' (p. 179).

From the metrical point of view, McNaughton defines 'a happy experience as an experience preferable to a moment of unconsciousness, an unhappy experience as one to which a moment of unconsciousness is preferable' (p. 176). There are some parallels here with what the philosopher G.E. Moore said about the relationship of pain and pleasure to desire. A major difference between pain and pleasure is that when one is in pain, one desires 'to be rid of the sensation in question . . . that so and so should cease to be the case ... to avoid it' (Moore, 1962, p. 31). So, Moore's solution would be similar to McNaughton's if one were unconscious of the pain. These views are in line with those who exposed consciousness as a method to realization, and perhaps lend support to Sigmund Freud's theory that the unconscious contains archetypes that upset the conscious states. But they would be at odds with Carl Jung's theory that the unconscious is a source of creativeness, which seeks an expression.

On the economic side stand those who use pairwise preference to reach the maximum statistical happiness, those who use preference relationships to expound a rational ground for decision-making, and those who use them to prove that a democratic society is impossible.

An update of McNaughton's axioms for modern information modeling shows a major inconsistency. It relates to how observers partition information in intervals of time. This work was started by the philosopher David Lewis and was most notably brought to economics by Robert Aumann. These views are presented in 'Common Knowledge', by Werlang (1989). Basically, two observers looking at the same accident for instance are likely to give different police reports. The difference is because one partitions the information in small slots, while the other does so in large slots. In economic jargon, one takes a microeconomic perspective while the other takes a macroeconomic perspective. Because of the 'fallacy of composition', the micro perspective does not generalize in a straightforward way to the macro perspective.

One may question McNaughton's time moment axioms by arguing for a space axiom as well. The intention of the space-time axiom is for one to worry more about the one dimension that he used for the time-moment axiom. But there is a question as to whether happiness in the form of bliss, satori, reveries, nirvana, and Brahman as expounded in several spiritual followings are subject to space-time analysis. One reads that conscious realization is unbounded, and therefore not subject to metamorphosis.

It is not uncommon for economists to refer to bliss states. Frank Ramsey 
proposed an early measure of the state of bliss in economics that is still relevant for modern research (Ramsey, 1928). His theory shows how lifetime consumption and savings converge to that state. Two famous macroeconomic models have dominated the economic literature since then: namely, the monetarist and the Keynesian. The monetarists seek to control the economy through monetary rules that would tie the supply of money to the growth rate of productivity. Such a control would stabilize the economy.

Keynesians, however, look at the economy as a state of harmony where the activities in different sectors such as the monetary, real, labor, and production are synchronized. Deviation from such a harmonious state would permit government discretionary policies in bad states such as recession and depression, but the market would take over upon recovery. Keynes developed this short-term harmonious model in his famous book The General Theory of Employment (Keynes, 1972-89, Vol. VII). Prior to that work, Keynes wrote about the long-term view in his 'Economic Possibilities for our Grandchildren' (Keynes, 1972-89, Vol. IX). The longrun view of Keynes, based on science and technology, predicted a four- to eightfold increase in standard of living over 100 years from 1930.

\section{HAPPINESS IN LITERATURE}

In the novel The History of Rasselas: Prince of Abyssinia, Samuel Johnson (1889) gave an account of the prince's pursuit of happiness. Rasselas lived in the Valley of Happiness. One day he decided to pursue happiness in the outer world and decided to journey outside the valley. He discovered several truths about happiness. First, we need mental stimulation to confront stagnation of life; second, no one is perfectly happy; third, pleasure cannot gratify the infinite desire of the longing soul, and therefore one should seek some employment (Kalpakgian, 2018).

Johnson's theories of happiness hold that a person should not 'neglect the study of himself, the knowledge of his own station in the ranks of being, and his various relations to the innumerable multitudes which surround him, and with which his Maker has ordained him to be united for the reception and communication of happiness' (Probyn, 1978, p. 259). This view is based on modern ethical concerns since John Locke, selfknowledge, and the practice of Christian piety (p. 259).

A now popular book on happiness is The Art of Happiness (Dalai Lama and Cutler, 1998). While the book is by a Western psychiatrist and a Buddhist monk, it speaks to all human beings. The opening pages state that: 'we are all human beings ... Our physical structure is the same and 
our mind and our emotional nature are also the same' (p. 2). The solution to unhappiness is sought in gentleness, goodness, compassion, kindness, and a sense of commonality among all humans (p. 8). The Western approach limits their search for happiness to the conscious and unconscious mind in one lifetime, while the Buddhist goes back to many lifetimes and remains optimistic and realistic.

The Art of Happiness gives some propositions that seem free of religious dogma. We may take it as a paradigm for happiness. They are based on morals in many historical schools of thought. Observations of compassion and love, as for instance parents for a child or between friends, give one the general idea that humans are by nature capable of attaining happiness. The function of awareness, which we all have, is the primary tool for the mind to attain that state. But one has to invoke determination and the human will and make effort towards progress. As we go through happiness from the economic standpoint, we will look for some of the following propositions at work:

1. The purpose of existence is to seek happiness (p. 16).

2. Happiness is determined more by one's state of mind than by external events (p. 20).

3. Our feelings of contentment are strongly influenced by our tendency to compare (p.22).

4. The true antidote of greed is contentment (p.29).

5. Human bonds can give rise to a sense of worth and dignity (p. 31).

6. Right now, at this very moment, we have a mind, which is all the basic equipment we need to achieve complete happiness (p. 31).

7. Maintain a feeling of compassion, loving kindness, then something automatically opens your inner doer (p. 40).

8. We must develop an appreciation and awareness that our human nature is fundamentally gentle and compassionate (p.48).

9. To make war or act violently is not genetically programmed into human nature (p. 58).

10. Realizing the value of compassion and then cultivating it is favored over working on social skills or external behavior (p. 71).

11. In relationships, the first stage involves deliberately reflecting on the underlying nature and basis of the relationship; bases of wealth and power versus human feelings of closeness, sharing, and connectedness (p. 99).

12. Transform our attitude towards suffering and adopt an attitude that allows greater tolerance of it (p. 140).

13. We often add to our pain and suffering by being overly sensitive, overreacting to minor things, and sometimes taking things too personally (p. 152). 
14. It is a process of learning, training, and getting used to new viewpoints that enables you to deal with difficulties (p. 176).

15. Learning with awareness leads to conviction, in turn leading to a determination to change, which then needs effort to lead to a new habit pattern (p. 220).

16. If you encounter problems or obstacles, stand back and take a longterm over a short-term view (p. 226).

17. Make a distinction between your ideals and the standards by which you judge your progress (p. 232).

18. We have a capacity to isolate parts of ourselves that we seek to eliminate and do battle with them, based on our capacity to adopt different perspectives (p. 236).

19. Our positive states of mind can act as antidotes to our negative tendencies and delusory states of mind (p. 239).

20. Being honest with oneself and others about what you are or are not capable of doing can counteract a lack of self-confidence. Honesty and self-confidence are closely linked (pp. 280-281).

21. All individuals sincerely wish for their own happiness (p. 286).

22. In some sense, we have the capacity for and intelligence of mental health, based on our knowledge, awareness, and positive determinations (pp. 289-299).

\section{SCOPE OF HAPPINESS}

Ancient thoughts on happiness are linked with the idea of the supreme good. According to the philosopher Immanuel Kant, 'The supreme created good is the most perfect world, that is a world in which all rational beings are happy and are worthy of happiness' (Kant, 1963, p.6). This implies that there are some ethical considerations underlying happiness. If one attains happiness through unjust means, then one will be unworthy of happiness. Seen from the point of the ancient's concept of the supreme good, wealth and health are needed for well-being, but they must be coupled with merit or well-doing as well.

The unity of well-being and well-doing can be traced to the Cynic's concept of simplicity and the Epicurean's on prudence. As we shall show in the next chapter, other schools such as the Sophist were linked to Socrates, Plato, and Aristotle and anchored those concepts in knowledge and wisdom. For instance, wise persons hankered after the truth, and grasp things further removed from the senses. This contrasts with the Cyrenaics who seek pleasure.

Many schools have considered happiness as a state of mind. One major 
exception is Ludwig Wittgenstein, who held that the world is the totality of facts and not state of mind, which we will examine in Chapter 2. For the state of mind view, we gather data from the gateways of our senses to create images. Many images combine over time into ideas, says Hume (1992 [1740], p.4). The human mind is constantly going over these ideas, perhaps overacting, being too sensitive, or perhaps not allocating time to love and to be. Out of that process, vice and virtue that make up the classic summum bonum or supreme good arise, not from reason, but from feelings (p. 479).

As for the path to happiness, Bertrand Russell wrote: 'It is a commonplace that happiness is not best achieved by those who seek it directly' (Russell, 1957 [1917], p.29). He explained that people seek to know the world 'through the distorting medium of their own desires'. One should rather seek the facts (p.29). Russell held a propositional theory of facts, while Wittgenstein held a picture theory. On the one hand, some ancient philosophers such as Heraclitus and Plato taught mysticism, 'a certain intensity of depth and fillings in regard to what is believed about the universe' (p. 2). On the other hand, Parmenides' advice to Plato 'not to despise even the meanest things', Russell called 'the genuine scientific temper' (p.7). Russell's view was that temper involves a marriage of our ideals with the world (p. 7). This view is exemplified in his other work, The Conquest of Happiness, where he gave commonsense guidance to conquer unhappiness relating to family, work, love, health, and charity (Russell, 1939, p. 198).

Russell stated that our conception should be related to space, time, matter, and cause (Russell, 1957 [1917], p. 130). We are concerned with cause when we say that happiness depends on our state of mind, which is an 'assemblage of particulars' of matter in the mind. Russell thought of entities in the world, particulars, as analogous to notes in a symphony that have time duration. Such matters call for a distinction to be made between mental and physical states. Mental means believing, doubting, wishing, willing, being pleased or pained, and general perceiving (p. 125).

Amartya Sen was concerned with some ambiguity with the concept of space and poverty: inequality. There is a problem of the choice of 'evaluative space' distributed over many variables: income, wealth, utilities, resources, liberties, rights, quality of life, and so on (Sen, 1991, p.4). This matter was also broached in his work on 'The Standard of Living', where he wrote: 'Within the general notion of the living standard, divergent and rival views of the goodness of life co-exist in an unsorted bundle' (Sen, 1998 [1987], p. 1). He wrote of being well off without being well, or being happy without freedom.

Generally, Sen looked into the philosophical and economic sides and made two distinctions of utility theory. From the side of revealed 
preference, utility is seen as something to maximize, 'the maximand of a person's choice behavior', while the other view represents 'the person's self-interest or well-being ... (or even the welfare) of a person' (Sen, 2002, p. 27). It appears that Sen is arguing for a contemporary research programme in the utility and welfare economic area. The utility-based theory in welfare economics has degenerated, but he noted that 'the decline of utilitarianism has not led to the rise of a freedom-oriented perspective' (p. 8). Some progress has already been made in measurements in the form of levels of living, base need fulfillment, quality of life, or human development, but they are not well founded on well-being or freedom concepts (p.8).

Frederick Hayek has written a lot against social justice in his research programme of the economic world of physical and sensory order (Hayek, 1976 [1952]). His methodological individualism believes that only the individual has access to information for economic choices. The information for people's decision-making is stored in a person's 'neural order' which belongs to the brain, a physical domain. A person knows best what is good for their happiness. Injustice occurs when another, a social planner of government, interferes intentionally with a person's judgment without their consent. Coercion produces injustice, and it is the state's function to remedy that. Bad luck and misfortune depend on the charity, altruism, humanity, and so on, of others.

One of the oldest concepts of happiness is tied up with love. According to Gottfried Leibniz, 'to love is to take delight in the happiness of another, or, what amounts to the same thing, it is to regard another's happiness as one's own' (Leibniz, 1951, p. 559). Again, 'Love is this act or active state of the soul which makes us find our pleasure in the happiness or satisfaction of others' (p. 564). Sometimes we perceive a beautiful object that produces happiness, and those affections become pure love (p. 560), but love of God surpasses all other love because it is divine. It yields the greatest results, is the most beautiful, the worthiest, and has the greatest power and wisdom. 'Wisdom is nothing else than the very science of happiness' (p. 560). Such a science is just as well, for 'Justice is fundamentally nothing else than charity conformed to wisdom' (p. 560). To sum up his views on love, Leibniz states the following: 'Justice is the charity of the wise; Charity is general benevolence; Benevolence is the habit of love; To love anyone is to delight in his happiness; Wisdom is the science of happiness; Happiness is durable joy; Joy is the state of pleasure; Pleasure or delight is a sense of perfection' (pp. 568-576).

The highest state of happiness or bliss is generally stated as a Godly quality. Such a quality or state escapes a definition, but looked at from the point of view of human beings, we can consider it as belonging to a state 
of mind. This work is not just an appraisal of contemporary research on happiness sprouting from utility analysis. It accepts the two strands of utility trends that Sen has identified, including topics in the new direction that the field is tending towards. If happiness is something invented by man, then we can ascertain its limits and originality, but it appears as philosophical or empirical concepts to people. If empirical, we will fail to know its limits or origins. If it is an a priori philosophical concept, we can always doubt its completeness. More and more examples of it can only make it probable, but not certain (Caygill, 1995, p. 153).

The concept of happiness in Greek writings seems to be a condition on the good life. Today we are divided between looking for happiness inwardly or outwardly. The former is the preferred approach of the spiritually inclined, and the latter is the preferred approach of most scientists. Early approaches to the utility theory of happiness took a subject approach. Later approaches such as the revealed preference theory tried to make it objective by using consumer choices as data. Earlier, Pareto had taken the whole indifference curve approach as data to set economics on a scientific basis to build the theory of choice (Mitchell, 1969, p. 412).

\section{OUTLINE OF THE BOOK}

\section{Chapter 1: Introduction and General Overview of Economic Happiness}

In this first chapter, we painted the background upon which we will draw our economic concepts of happiness. We found the domain of the concept to be an open set of ideas. The concept of utility is prominent in that domain and is of paramount importance in the development of economics. It concerns the happiness of individuals and society, which have measurement challenges. One may take a subjective or objective approach to economic happiness based on one's inclination. That is the bird's eye view of the project at hand, which is elucidated in different chapters specializing on the substantial ideas found in the literature.

\section{Chapter 2: Ideas (Fundamental) of Happiness and Well-being: Ancient, Medieval, and Modern}

This chapter builds on some major moral and philosophical theories from the ancient, medieval, and modern schools that form the foundation of utility analysis. Greek thought on happiness had been the foundation for the study of happiness. The thinkings are most linked to ethical aspects, although every other aspect, such as political, legal, and philosophical, 
also matters. We start with the Sophist school, with dialectical reasoning about happiness, which was picked up by Socrates, Plato, and Aristotle. Those ideas are then contrasted with the Cyrenaic, Cynics, Epicureans, and Stoics. A figure is included of the intercorrelation of Greek thought on happiness.

\section{Chapter 3: Economics and Happiness}

In this chapter, we look at some broad sources of the economics of happiness. Starting with a classification of the subject based on psychological, individual, social, and institutional views of happiness, we then move to how the historical schools of thought explicitly or implicitly deal with the matter.

\section{Chapter 4: Subjective Studies in Income and Wealth: Can Money Buy Happiness?}

The objective of this chapter is the study of theories and measurement of subjective well-being. The works of Richard Easterlin and Angus Deaton, using the survey methodology of Hadley Cantril and the Gallup Poll, as well as Daniel Kahneman, take up the study of the long- and short-term structures of the mind. Positive theory such as the prediction by Paul A. Samuelson of consumer preferences from their consumption pattern are studied. John von Neumann and Oskar Morgenstern's axiomatic utility framework is investigated as the foundation of modern analysis of utility.

\section{Chapter 5: Social Welfare and Happiness}

In this chapter, we direct our study of happiness to that of society and the welfare of mankind. This requires focusing on social relationships and the social skills, ties, and support that may contribute to happiness. Humans find happiness by participating in groups. The concept of group rationality reveals that each individual gets benefits from such membership. For instance, you may not be able to adequately protect yourself and your property, so you turn to society. The will of individuals guards self-interest, but there is a general will which guards common interest, according to Jean-Jacques Rousseau (1978, p. 72). The general will is a compelling force, and may not work in a way to provide individual happiness. There are many theories associated with a happy society. 